\title{
Lise Öğrencilerinin STEM'e Yönelik Tutumlarının İncelenmesi
}

\author{
DOI: 10.26466/opus.547459 \\ * \\ Serpil Özkurt Sivrikaya
}

* Dr, Öğr. Üyesi, Kocaeli Üniversitesi, Kocaeli Meslek Yüksekokulu, Başiskele / Kocaeli / Türkiye

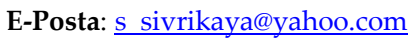

ORCID: 0000-0003-0352-243X

\section{Öz}

$B u$ araştırmanın amacı, Fen Bilimleri eğitiminde lise öğrencilerinin STEM'e yönelik tutumların ölçmektir. Araştırma Kocaeli ilinde yer alan bir Anadolu lisesinde yapılmıştır. Araştırma 404 öğrenci üzerinde gerçekleştirilmiştir. Araştırma kapsamına 9. sınıf ve 10. sını öğrencileri dahil edilmiştir. Araştırmada nicel yöntem tercih edilmiştir. Araştırmada matematik, fen, teknoloji ve 21. Yüzyll becerilerinden oluşan dört boyuttan STEM tutum ölçeği kullanılmıştır. Ölçeğin güvenirlik kat sayısı 0,841 olarak bulunmuştur. Ölçek maddeleri 36 sorudan oluşmaktadır. Analizler SPSS 21 programı ile yapılmıştır. Araştırmaya katılan öğrencilerin \% 40,6'sı erkek, \% 59,4'ü kadındır. Öğrencilerin cinsiyeti ile STEM ve alt boyutu olan teknoloji ile 21. Yy becerileri arasında anlamlı bir ilişki bulunmuştur. Baba eğitim düzeyi ile STEM ve alt boyutu olan teknoloji arasında bir ilişki tespit edilmiştir. Öğrencilerin sınf düzeyleri, anne eğitim düzeyi ve gelirleri ile STEM tutumları arasında anlaml bir ilişki bulunamamıştır. Ayrıca ilgili okulda eğitim müfredatının içerisinde ders olarak verilmemesine rağmen robotik kodlama ve akul oyunları kulüplernin olduğu datespit edilmiştir.

Anahtar Kelimeler: STEM, Tutum, Lise Öğrencileri 


\title{
Research of High School Students' Attitudes of STEM
}

\begin{abstract}
In this study, it is aimed to scale high school students' attitudes of STEM. The research was conducted at an Anatolian high school in Kocaeli. The research was conducted on 404 students. 9th grade and 10th grade students were included in the study. Quantitative method was preferred in the study. In this study, STEM attitude scale was used in four dimensions which were math, science, technology and 21st century skills. The reliability coefficient of the scale was found to be 0,841 . Scale items consisted of 36 questions. The analyzes were performed with SPSS 21 program. $40.6 \%$ of the students were male and $59.4 \%$ were female. There was a significant relationship between the gender of the students and STEM and its sub-dimension and the 21st century skills. A relationship was found between the level of father education and STEM and its sub-dimension technology. No significant relationship was found between the student' class levels, mother education level and income and STEM attitudes. In addition, although it was not given as a lecture in the related school curriculum, there were robotic coding and mind games clubs.
\end{abstract}

Keywords: STEM, Attitude, High School Students. 


\section{Giriş}

Toplumsal yapının değişimi ile birlikte sanayi toplumundan bilgi toplumuna doğru yöneliş söz konusu olmuştur. Bilgi toplumlarında esas olan, bilgiyi üretmektir. Bilgi üretmek dünyayı yönetmeye eşdeğerdedir. STEM okuryazarlığı, her vatandaşın kişisel refahı için ve ülkenin küresel ekonomideki rekabet edebilirliği için önemlidir (Beatty, 2011). Bilgiyi üretebilmenin yolu ise eğitimden geçer. Bu açıdan $A B D$ 'nin öncülük ederek eğitim alanında gerçekleştirdiği STEM (Science, Technology, Engineering, Mathematics) eğitime yenilikler katmıştır.

STEM; disiplinler arası ve uygulamalı bir yaklaşım olarak öğrencileri dört özel disiplinde (bilim, teknoloji, mühendislik ve matematik) yetiştirme esasına dayanan bir müfredattır. Dört disiplini ayrı ayrı öğretmek yerine gerçek dünyadaki uygulamalara dayanan tutarlı bir öğrenme paradigması ile öğretilmesi esasına dayanır (Hom, 2014). "Fen ve matematik teorik bilgilerinin mühendislik boyutunda desteklenerek tek bir ürün elde edilmesidir" (TÜZÜYEKSAV, 2016).

STEM eğitimi aslen fen, matematik, mühendislik ve teknoloji (SMET) Ulusal Bilim Vakfı tarafından yaratılmış bir girişimdir. Bu eğitim girişimin amac1; tüm öğrencilere eleştirel düşünme sağlamak, onları yaratıcı problem çözücü haline getirerek işgücü pazarlanabilirliği artıracak beceriler kazandırmaktır (White, 2014, s.1). Bilgi tabanlı ve son derece teknolojik toplumun zorluklarıla başa çıkmak için gerekli beceri ve yetkinliklere sahip olmalıdır. (Thibaut vd., 2018, s.1)

Bilim: Malzemenin doğası, sistematik çalışması, gözlem, deney ve ölçüme dayalı fiziksel evren ve bu gerçekleri tanımlamak için yasaların oluşturulmasını ifade eder.

Teknoloji: Yaşam, toplum ve çevre ile ilişkileri için gerekli teknik araçlar oluşturulması ve kullanımı ile ilgilenen bilgi dalıdır.

Mühendislik: Bilginin uygulanabilirliği, pratik yapma sanatıdır.

Matematik: Cebir, geometri ve matematik, sayı, nicelik, biçim, mekan çalışmaları ve özel gösterim kullanarak karşılıklı ilişkiler kurma, kavrama becerisini (Bruton, 2017) temsil etmektedir.

Stem eğitimi; problemlerin yaratıcı bir şekilde çözülebilmesi için becerileri ve içerik bilgilerini kullanma, hayal etme, sorgulama, analiz etme, 
keşfetme, takım halinde çalışabilme, yenilik ve tasarım yaratabilmeyi amaçlamaktadır (Bruton, 2017, s.7).

2015 Yılında Kimya Nobel ödülünü alan Prof. Dr. Aziz Sancar; üniversite ve araştırma laboratuvarlarında kullanılan malzemelerin Hollanda, $\mathrm{ABD}$, Japonya gibi ülkelerde üretildiğini belirtmiştir. Bu malzemeler Türkiye'de neden üretilmiyor? sorusunu sormuştur. Üretilmeme nedeni olarak temel bilimlere yatırım yapılmamasını göstermiştir. "Temel bilimler ihmal edilince beyin göçü gerçekleşti, ilgili malzemeleri yaratacak iş gücü kaybedilince üreten bir ülke olamayı" demiştir (TÜZÜYEKSAV, 2016). STEM eğitimleri okul öncesinden lise seviyesine kadar verilebilmektedir. STEM eğitimlerini üniversitede devam ettirmek isteyen öğrenciler üstün başarılı göstermektedirler.

STEM'in açılımı incelenecek olursa, bilim; dünyanın doğal çalışma yapısını anlamak, teknoloji; insan ihtiyaçlarını ve isteklerini karşılamak için değişim yaratmak, mühendislik; matematik ve fen bilimlerini uygulayarak teknoloji yaratmak, matematik; sayılar, işlemler, desenler ve ilişkilere odaklanır (Bruton, 2017, s.7).

Kız öğrenciler açısından STEM uygulamalarında özellikle mühendislik işlerinin tanımlanmasında sorunlar olduğu belirlenmiştir (Yıldırım ve Türk, 2018). Akçapınar ve Coşgun (2018) çalışmalarında öğrencilerin yarıdan fazlasının steme yönelik kariyer tercihinde bulunacakları tespit etmişlerdir. Gülhan ve Şahin (2016), öğrencilerin STEM uygulamalarına karşı tutumlarını ölçtükleri araştırmada STEM uygulamalarının öğrencilerin gelişimini olumlu yönde etkilediğini belirlemişlerdir (akt., Güven vd., 2018, s.77). Fen alanındaki teknoloji, toplum, çevre, sanatsal tasarım gibi yaklaşımlar öğrencilerin gelişimlerini olumlu yönde etkilemektedir (Batı vd., 2017, s.94). Yıldırım ve Altun (2015), STEM eğitiminin öğrenci başarısına katkıda bulunduğunu araştırmaları sonucunda tespit etmişlerdir (akt. Biçer vd., 2018). Örneklem büyüklüğü ölçek maddesi sayısına oranlandığında elde edilen verilerin genellebilir bir yapıya sahip olduğunu belirtmek mümkündür (Derin vd., 2017, s.549).

STEM'in öğrencilere katkısı 21. Yüzyıl becerileri kazanma, STEM disiplinleri arasında bağlantı kurabilme becerisi iken eğitimcilere katkısı STEM içeriği ve STEM hakkındaki pedagojik bilginin artırılmasıdır (Honey vd., 2014; akt. Gencer vd., 2019, s.49). 
Gülen ve Yaman (2018) araştırmalarında grup üyelerinin STEM disiplinlerinin yardımıyla argüman oluşturduklarını belirlemişlerdir. Yıldırım (2017) öğretmen adaylarını örneklem aldığı çalışmasında, öğrencilerin STEM öğretimi hakkında olumlu görüşlerde bulunduklarını belirlemiş, öğrencilerin robotik programlama, laboratuvar uygulamaları gibi bilim, matematik ve tasarım odakları derslerin eksikliğinden yakındıklarını tespit emiştir. Türkiye'de STEM eğitimi uygulamaları ve çalışmaları yapılmasına rağmen bu modelin tam olarak kullanılması henüz gerçekleştirilememiştir (Yılmaz vd., 2017, s.1790).

Benek ve Akçay (2018) çalışmalarında öğrencilerin STEM kullanma oranlarıyla sınıf düzeyleri arasında doğru yönlü bir ilişki bulmuşlardır. Amerika ve diğer gelişmiş ülkelerde geleceğin mühendislerinin çocukluk dönemlerinde blok oyuncuklarla köprüler kurduklarına dikkat çekerek STEM eğitimini anasınıfından başlatmaktadırlar. Genç neslin keşfederek öğrenmesi ve bilimsel analiz becerisine sahip olmaları STEM eğitimi ile başarılabilmektedir (Uyanık Balat ve Günşen, 2017, s.344). Çevik (2018)' in araştırmasında ders ortamında STEM uygulamalarının akademik başarıyı ve mesleki ilgiyi artırdığı bulunmuştur.

Globalleşen dünyada tüm ülkelerin hedefi STEM alanında kendini geliştirerek STEM eğitimi ile öğrencileri desteklemek ve lise eğitimi süresince STEM eğitimini etkin bir şekilde uygulamayı başarmaktır (Eroğlu ve Bektaş, 2016, s.44). STEM eğitiminde kurumsal açıdan alt yapının sağlanamadığı, uygulama ve hazırlık yapılmadığı tespit edilmiştir (Çolakoğlu ve Gökben, 2017). Fen laboratuvarı uygulamalarıyla öğrencilerin STEM becerilerinin geliştirilebileceği bulunmuştur (Gökbayrak ve Karışan, 2017, s.74). Daşdemir vd. (2018, s.1161) yapmış oldukları çalışmada Türkiye'de STEM'le ilgili yapılan araştırmalarda amaçlı örnekleme yöntemi kullanılarak yapıldığını, örneklem grubu olarak ortaokul öğrencilerinin tercih edildiğini, bilgi-beceri-başarı testleri ile görüşmenin veri toplama aracı olarak kullanıldığını, analiz yöntemi olarak da içerik analizinin tercih edildiğini tespit etmişlerdir.

\section{Araştırmanın Yöntemi}

Araştırma lise öğrencilerinin STEM'e yönelik tutumlarını ölçmek amacıyla kurgulanmıştır. Nicel araştırma yöntemi benimsenerek anket 
çalışmasının yapıldığı çalışmada STEM tutum ölçeği kullanılmıştır.

Lise öğrencilerinin STEM'e yönelik tutumlarını ölçmek için, Friday Eğitimde Yenilikçi Uygulamalar Enstitüsü (2012)'nün geliştirdiği ölçeğin Türkçe'ye uyarlama çalışmasını Özcan ve Koca (2019) tarafından yapılmıştır. Anketin birinci bölümü STEM tutum ölçeğinden oluşmaktadır. 37 maddelik ölçeğe ilişkin sorular 5'li likert şeklinde hazırlanmıştır. Katılımcıların ölçek sorularını "Kesinlikle Katılmıyorum (1)" ile "Kesinlikle Katılıyorum (5)" şeklinde cevaplamaları istenmiştir. Öğrencilerin STEM tutumlarının ölçüldüğü anketin ikinci bölümünde öğrencilerin cinsiyet, sınıf, anne-baba eğitim düzeyi ve gelir durumunu tespit etmek amaciyla demografik sorular sorulmuştur.

\section{Bulgular}

Araştırmanın ana kültesini Kocaeli İli Körfez İlçesinde yer alan Anadolu Lisesinde öğrenim gören öğrenciler oluşturmaktadır. Araştırma ilgili okulda 2018-2019 eğitim öğretim döneminde öğrenim gören 9.-10. sinıf öğrencilerine uygulanmıştır. Örneklemi 404 öğrenci oluşturmaktadır. Analizler SPSS 21 programı kullanılarak yapılmıştır, anlamlılık derecesi 0,05 kabul edilmiştir.

Tablo 1. Faktör analizi KMO ve Barlett testi

\begin{tabular}{lll}
\hline KMO & 0,88 \\
\hline Barlett Testi & Sd & 630 \\
\hline Sig & 0,00 \\
\hline
\end{tabular}

Kaiser-Meyer-Olkin (KMO) katsayısı ve Barlett Sphericity testi sonuçları verilerin faktör analizi için uygun olduğu göstermektedir. Faktör analizi sonuçlarına göre örneklem hacminin yeterli olduğu görülmektedir. 
Tablo 2. Tekrarlanan faktör analizi döndürülmüş̧ bileşenler matrisi

\begin{tabular}{|c|c|c|c|c|c|}
\hline Ölçek Maddeleri & 1. Faktör & 2. Faktör & 3. Faktör & 4. Faktör & $\bar{X}$ \\
\hline F2 & 810 & & & & 3,26 \\
\hline F5 & 778 & & & & 3,22 \\
\hline F4 & ,775 & & & & 3,54 \\
\hline F7 & ,766 & & & & 3,31 \\
\hline F6 & 744 & & & & 3,55 \\
\hline F9 & 737 & & & & 2,96 \\
\hline F1 & 734 & & & & 3,45 \\
\hline F3 & ,551 & & & & 3,24 \\
\hline F8 & 424 & & & & 2,13 \\
\hline M8 & & ,817 & & & 3,39 \\
\hline M5 & &,- 775 & & & 2,31 \\
\hline M3 & &,- 771 & & & 2,46 \\
\hline M4 & & ,758 & & & 3,31 \\
\hline M1 & &,- 726 & & & 2,27 \\
\hline M7 & & ,695 & & & 3,71 \\
\hline M6 & & ,650 & & & 2,74 \\
\hline M2 & & ,568 & & & 3,30 \\
\hline T6 & & & ,767 & & 3,64 \\
\hline T4 & & & ,739 & & 3,64 \\
\hline T9 & & & 694 & & 3,09 \\
\hline T5 & & & 682 & & 3,27 \\
\hline T3 & & &, 588 & & 3,16 \\
\hline $\mathrm{T} 2$ & & & ,556 & & 3,33 \\
\hline T8 & & & ,520 & & 3,58 \\
\hline T7 & & & ,489 & & 3,96 \\
\hline $\mathrm{T} 1$ & & & ,382 & & 3,75 \\
\hline BC2 & & & & 695 & 3,73 \\
\hline BC8 & & & & 651 & 3,97 \\
\hline BC1 & & & & ,635 & 3,55 \\
\hline BC5 & & & & 620 & 4,37 \\
\hline BC9 & & & & ,593 & 3,63 \\
\hline BC10 & & & & ,558 & 3,94 \\
\hline BC11 & & & & ,546 & 3,92 \\
\hline BC6 & & & & ,403 & 4,01 \\
\hline BC3 & & & & ,382 & 3,99 \\
\hline BC4 & & & & ,335 & 4,57 \\
\hline
\end{tabular}


Elde edilen verilere faktör analizi uygulanmıştır. 21. yüzyıl becerileri boyutunda "işler planlandığı gibi gitmediğinde değişiklikler yapabileceğimden eminim" ifadesinin faktör yük değeri $0,27<0,30$ olduğundan analizden çıkarılmıştır. 0.30' a kadar faktör yük değeri yeterli büyüklük olarak kabul edilebilmektedir (Büyüköztürk, 2002). Tekrarlanan faktör analizi sonuçları Tablo 2'de gösterilmiştir. Tekrarlanan faktör analiziyle açıklanan varyans oranı 58,863'ten 60,146'ya çımıştır.

Tablo 3. Ölçek güvenirlik katsayısı

\begin{tabular}{lcc}
\hline Faktör & Madde & Güvenirlik Cronbach \\
& & Alfa \\
STEM tutum ölçeği & 36 & 0,841 \\
\hline
\end{tabular}

Ölçeğe ait güvenirlik analizi sonuçları tablo 3' te gösterilmiştir. Ölçek güvenilirlik katsayısı $\geq 0.9$ arası mükemmel, $0.9 \leq \alpha \leq 0.7$ arası iyi, $0.7 \leq \alpha \leq 0.6$ arası kabul edilebilir, $0.6 \leq \alpha \leq 0.5$ arası zayıf, $\leq 0.5$ arası kabul edilemeyecek (Kılıç, 2016, s.48) bir büyüklüğü göstermektedir. Belirtilen büyüklükler için ölçek güvenirliğinin iyi derecede olduğu görülmektedir.

Tablo 4. STEM Tutum ölçeği ve boyutları arasındaki kolerasyon

\begin{tabular}{cccccc}
\hline & Matematik & Fen & Teknoloji & $\begin{array}{c}\text { 21.Becer- } \\
\text { ileri }\end{array}$ & STEM \\
STEM & $0,591^{* *}$ & $0,735^{* *}$ & $0,613^{* *}$ & $0,524^{* *}$ & 1 \\
\hline$* * p<0,01$ & & & & &
\end{tabular}

Ölçek ve ölçeğin alt boyutlarına ilişkin kolerasyon katsayıları tablo 4'te verilmiştir. STEM ölçeği matematik alt boyutu ile doğru yönlü ve orta düzeyde, fen alt boyutu ile doğru yönlü ve yüksek düzeyde, teknoloji alt boyutu ile doğru yönlü ve orta düzeyde, yirmi birinci yüzyıl becerileri alt boyutu ile doğru yönlü ve orta düzeyde bir ilişkiye sahiptir.

Öğrencilerin \% 40,6' sının erkek \% 58,4'ünün kadın olduğu görülmüştür. Öğrencilerin anne eğitim düzeylerinin \% 51,7' sinin ilköğretim mezunu olduğu, \% 41,6'sının baba eğitim düzeyinin lise mezunu olduğu görülmüştür. Öğrencilerin aile gelir durumları incelendiğinde \% 28,2' sinin 2001-3000 TL arası gelire sahip olduğu tespit edilmiştir. Ayrıca öğrencilerin \% 61,1' inin 9. sınıf, \% 38,9' unun 10. sinıfta öğrenim gördüğü belirlenmiştir. 
Tablo 5. Demografik değişkenlere ait tanımlayıcı bilgiler

\begin{tabular}{|c|c|c|}
\hline Değişkenler & $\mathbf{N}$ & $\%$ \\
\hline \multicolumn{3}{|l|}{ Cinsiyet } \\
\hline Erkek & 164 & 40,6 \\
\hline Kadın & 240 & 59,4 \\
\hline \multicolumn{3}{|l|}{ Anne eğitim durumu } \\
\hline İlköğretim & 209 & 51,7 \\
\hline Lise & 150 & 37,1 \\
\hline Önlisans & 22 & 5,4 \\
\hline Lisans & 18 & 4,5 \\
\hline Yükseklisans-Doktora & 5 & 1,2 \\
\hline \multicolumn{3}{|l|}{ Baba eğitim durumu } \\
\hline İlköğretim & 148 & 36,6 \\
\hline Lise & 168 & 41,6 \\
\hline Önlisans & 40 & 9,9 \\
\hline Lisans & 41 & 10,1 \\
\hline Yükseklisans-Doktora & 7 & 1,7 \\
\hline \multicolumn{3}{|l|}{ Gelir } \\
\hline 2000 TL ve alt1 & 59 & 14,6 \\
\hline 2001-3000TL & 114 & 28,2 \\
\hline 3001-4000TL & 87 & 21,5 \\
\hline 4001-5000TL & 49 & 12,1 \\
\hline 5001-6000TL & 51 & 12,6 \\
\hline 6001-7000TL & 44 & 10,9 \\
\hline 7001 TL ve üzeri & 0 & 0 \\
\hline \multicolumn{3}{|l|}{ Sinıf } \\
\hline 9. sinif & 247 & 61,1 \\
\hline 10.sinif & 157 & 38,9 \\
\hline
\end{tabular}

Verilerin normal dağılımına ilişkin yapılan normallik test sonucuna göre verilerin normal dağılmadığ metrik Mann Whitney U ile Kruskall Wallis H testleri uygulanmıştır.

Tablo 6. Cinsiyet ile STEM tutumu arasındaki ilişki

\begin{tabular}{|c|c|c|c|c|c|c|}
\hline & & $N$ & Stra ort. & Stratop. & $U$ & $P$ \\
\hline \multirow[t]{2}{*}{ STEM } & Erkek & 164 & 194,33 & 31870,00 & \multirow{2}{*}{18340,00} & \multirow{2}{*}{0,27} \\
\hline & Kadın & 240 & 207,26 & 49536,00 & & \\
\hline \multirow[t]{2}{*}{ Matematik } & Erkek & 164 & 204,79 & 33585,00 & \multirow{2}{*}{19305,00} & \multirow{2}{*}{0,74} \\
\hline & Kadın & 240 & 200,94 & 34050,00 & & \\
\hline \multirow[t]{2}{*}{ Fen } & Erkek & 164 & 207,62 & 47760,00 & \multirow{2}{*}{18840,00} & \multirow{2}{*}{0,46} \\
\hline & Kadın & 240 & 199,00 & 22786,00 & & \\
\hline \multirow[t]{2}{*}{ Teknoloji } & Erkek & 164 & 167,81 & 27521,50 & \multirow{2}{*}{27521,50} & \multirow{2}{*}{0,00} \\
\hline & Kadın & 240 & 226,20 & 54288,50 & & \\
\hline \multirow{2}{*}{$\begin{array}{l}\text { 21.yüzyıl } \\
\text { becerileri }\end{array}$} & Erkek & 164 & 220,92 & 36231,50 & \multirow{2}{*}{16494,50} & \multirow{2}{*}{0,00} \\
\hline & Kadın & 240 & 189,01 & 45174,50 & & \\
\hline
\end{tabular}


Yapilan Mann Whitney U testi analiz sonucunda; cinsiyet ile STEM arasinda bir ilişki olmadığ1 görülmektedir. Ancak cinsiyet ile STEM' in alt boyutu olan teknoloji $(p=0,00<0,05)$ ve 21 . Yüzyıl becerileri $(p=0,00<0,05)$ arasında anlamlı bir ilişki mevcuttur. Teknoloji alt boyutunda kadın öğrenciler (sıra ort= 226,20) erkek öğrencilere (sıra ort= 167,81) göre daha yüksek tutum göstermişlerdir. 21. Yüzyıl becerileri için erkek öğrenciler $($ sıra ort $=220,92)$ kadın öğrencilere (sıra ort $=189,01)$ göre daha yüksek tutum göstermişlerdir.

Tablo 7. Sınıf ile STEM tutumu arasındaki ilişki

\begin{tabular}{|c|c|c|c|c|c|c|}
\hline & & $N$ & Stra ort. & Stra top. & $U$ & $P$ \\
\hline \multirow[t]{2}{*}{ STEM } & 9. sinif & 247 & 206,93 & 50905,50 & \multirow{2}{*}{18097,50} & \multirow{2}{*}{0,28} \\
\hline & 10.sinif & 157 & 194,27 & 30500,50 & & \\
\hline \multirow[t]{2}{*}{ Matematik } & 9. sinif & 247 & 201,76 & 49835,50 & \multirow{2}{*}{19207,50} & \multirow{2}{*}{0,87} \\
\hline & 10.sinif & 157 & 203,66 & 31974,50 & & \\
\hline \multirow[t]{2}{*}{ Fen } & 9. sinif & 247 & 207,68 & 51297,00 & \multirow{2}{*}{18110,00} & \multirow{2}{*}{0,26} \\
\hline & 10.sinif & 157 & 194,35 & 30513,00 & & \\
\hline \multirow[t]{2}{*}{ Teknoloji } & 9. sinif & 247 & 207,56 & 51266,50 & \multirow{2}{*}{18140,50} & \multirow{2}{*}{0,27} \\
\hline & 10.sinif & 157 & 194,54 & 30543,50 & & \\
\hline \multirow{2}{*}{$\begin{array}{l}\text { 21.yüzyıl } \\
\text { becerileri }\end{array}$} & 9. sinif & 247 & 209,76 & 51602,00 & \multirow{2}{*}{16494,50} & \multirow{2}{*}{0,09} \\
\hline & 10.sinif & 157 & 189,83 & 29804,00 & & \\
\hline
\end{tabular}

Yapılan Mann Whitney U testi analiz sonucuna göre; sinıf düzeyi ile STEM ve alt boyutları arasında bir ilişki olmadığı görülmektedir.

Tablo 8. Anne eğitim düzeyi ile STEM tutumu arasındaki ilişki

\begin{tabular}{|c|c|c|c|c|c|}
\hline & & $N$ & Sira ort. & $X^{2}$ & $p$ \\
\hline \multirow{5}{*}{ STEM } & İlköğretim & 209 & 193,71 & \multirow{5}{*}{2,53} & \multirow{5}{*}{0,63} \\
\hline & Lise & 150 & 210,77 & & \\
\hline & Önlisans & 22 & 206,55 & & \\
\hline & Lisans & 18 & 208,50 & & \\
\hline & Lisansüstü & 5 & 240,30 & & \\
\hline \multirow{5}{*}{ Matematik } & İlköğretim & 209 & 197,59 & \multirow{5}{*}{2,63} & \multirow{5}{*}{0,62} \\
\hline & Lise & 150 & 206,89 & & \\
\hline & Önlisans & 22 & 199,73 & & \\
\hline & Lisans & 18 & 236,53 & & \\
\hline & Lisansüstü & 5 & 165,60 & & \\
\hline \multirow{5}{*}{ Fen } & İlköğretim & 209 & 201,77 & \multirow{5}{*}{2,03} & \multirow{5}{*}{0,72} \\
\hline & Lise & 150 & 204,63 & & \\
\hline & Önlisans & 22 & 174,14 & & \\
\hline & Lisans & 18 & 221,25 & & \\
\hline & Lisansüstü & 5 & 226,50 & & \\
\hline
\end{tabular}




\begin{tabular}{|c|c|c|c|c|c|}
\hline \multirow{5}{*}{ Teknoloji } & İlköğretim & 209 & 191,01 & \multirow{5}{*}{4,75} & \multirow{5}{*}{0,31} \\
\hline & Lise & 150 & 215,26 & & \\
\hline & Önlisans & 22 & 209,41 & & \\
\hline & Lisans & 18 & 208,17 & & \\
\hline & Lisansüstü & 5 & 249,40 & & \\
\hline \multirow{5}{*}{$\begin{array}{l}\text { 21. Yüzyıl } \\
\text { Becerileri }\end{array}$} & İlköğretim & 209 & 198,24 & \multirow{5}{*}{3,75} & \multirow{5}{*}{0,44} \\
\hline & Lise & 150 & 198,59 & & \\
\hline & Önlisans & 22 & 236,68 & & \\
\hline & Lisans & 18 & 215,67 & & \\
\hline & Lisansüstü & 5 & 258,90 & & \\
\hline
\end{tabular}

Yapılan Kruskall Wallis H testi analiz sonucuna göre; anne eğitim düzeyi ile STEM ve alt boyutları arasında bir ilişki olmadı̆̆ı görülmektedir.

Tablo 9. Baba eğitim düzeyi ile STEM tutumu arasındaki ilişki

\begin{tabular}{|c|c|c|c|c|c|}
\hline & & $N$ & Stra ort. & $X^{2}$ & $p$ \\
\hline \multirow{5}{*}{ STEM } & İlköğretim & 148 & 197,30 & \multirow{5}{*}{11,17} & \multirow{5}{*}{0,02} \\
\hline & Lise & 168 & 220,27 & & \\
\hline & Önlisans & 40 & 165,65 & & \\
\hline & Lisans & 41 & 172,61 & & \\
\hline & Lisansüstü & 7 & 242,07 & & \\
\hline \multirow{5}{*}{ Matematik } & İlköğretim & 148 & 201,98 & \multirow{5}{*}{7,32} & \multirow{5}{*}{0,12} \\
\hline & Lise & 168 & 216,68 & & \\
\hline & Önlisans & 40 & 168,05 & & \\
\hline & Lisans & 41 & 184,23 & & \\
\hline & Lisansüstü & 7 & 177,21 & & \\
\hline \multirow{5}{*}{ Fen } & İlköğretim & 148 & 193,42 & \multirow{5}{*}{9,20} & \multirow{5}{*}{0,05} \\
\hline & Lise & 168 & 219,35 & & \\
\hline & Önlisans & 40 & 166,91 & & \\
\hline & Lisans & 41 & 193,98 & & \\
\hline & Lisansüstü & 7 & 243,21 & & \\
\hline \multirow{5}{*}{ Teknoloji } & İlköğretim & 148 & 201,98 & \multirow{5}{*}{10,83} & \multirow{5}{*}{0,02} \\
\hline & Lise & 168 & 215,23 & & \\
\hline & Önlisans & 40 & 183,31 & & \\
\hline & Lisans & 41 & 159,70 & & \\
\hline & Lisansüstü & 7 & 268,36 & & \\
\hline \multirow{5}{*}{$\begin{array}{l}\text { 21. Yüzyıl } \\
\text { Becerileri }\end{array}$} & İlköğretim & 148 & 207,43 & \multirow{5}{*}{6,266} & \multirow{5}{*}{0,18} \\
\hline & Lise & 168 & 208,89 & & \\
\hline & Önlisans & 40 & 164,03 & & \\
\hline & Lisans & 41 & 186,72 & & \\
\hline & Lisansüstü & 7 & 229,00 & & \\
\hline
\end{tabular}


Yapılan Kruskall Wallis H testi analiz sonucuna göre; baba eğitim düzeyi ile STEM $(p=0,02<0,05)$ arasında bir ilişki olduğu görülmektedir. Baba eğitim düzeyi önlisans olan öğrencilerin STEM tutumları (sıra ort=165,65) en düşük, baba eğitim düzeyi yükseklisans-doktora olan öğrencilerin STEM tutumları (sıra ort=242,07) en yüksek düzeydedir. Ayrıca baba eğitim düzeyi ile STEM'in alt boyutu olan teknoloji $(\mathrm{p}=0,02<0,05)$ arasinda da istatistiksel bir ilişki mevcuttur. Baba eğitim düzeyi lisans olan öğrencilerin teknoloji tutumları (sıra ort=159,705) en düşük, baba eğitim düzeyi yükseklisans-doktora olan öğrencilerin teknoloji tutumları (sıra ort $=268,36)$ en yüksek düzeyde olduğu görülmüştür.

Tablo 10. Öğrencilerin aile geliri ile STEM tutumları arasındaki ilişki

\begin{tabular}{|c|c|c|c|c|c|}
\hline & & $N$ & Stra ort. & $X^{2}$ & $p$ \\
\hline \multirow{6}{*}{ STEM } & 2000 TL ve altı & 59 & 213,36 & \multirow{5}{*}{4,86} & \multirow{5}{*}{0,43} \\
\hline & 2001-3000TL & 114 & 208,67 & & \\
\hline & 3001-4000TL & 87 & 211,38 & & \\
\hline & 4001-5000TL & 49 & 193,58 & & \\
\hline & $5001-6000 \mathrm{TL}$ & 51 & 174,89 & & \\
\hline & 6001-7000TL & 44 & 191,56 & & \\
\hline \multirow{6}{*}{ Matematik } & 2000 TL ve altı & 59 & 227,48 & \multirow{5}{*}{6,38} & \multirow{5}{*}{0,27} \\
\hline & 2001-3000TL & 114 & 208,58 & & \\
\hline & 3001-4000TL & 87 & 195,47 & & \\
\hline & 4001-5000TL & 49 & 200,95 & & \\
\hline & $5001-6000 \mathrm{TL}$ & 51 & 174,09 & & \\
\hline & 6001-7000TL & 44 & 201,81 & & \\
\hline \multirow{6}{*}{ Fen } & 2000 TL ve altı & 59 & 207,02 & \multirow{5}{*}{1,85} & \multirow{5}{*}{0,86} \\
\hline & 2001-3000TL & 114 & 203,13 & & \\
\hline & 3001-4000TL & 87 & 213,74 & & \\
\hline & 4001-5000TL & 49 & 196,79 & & \\
\hline & 5001-6000TL & 51 & 192,44 & & \\
\hline & 6001-7000TL & 44 & 190,60 & \multirow{7}{*}{3,91} & \\
\hline \multirow{6}{*}{ Teknoloji } & 2000 TL ve alt1 & 59 & 208,90 & & \multirow{6}{*}{0,56} \\
\hline & 2001-3000TL & 114 & 199,39 & & \\
\hline & 3001-4000TL & 87 & 220,34 & & \\
\hline & 4001-5000TL & 49 & 189,86 & & \\
\hline & $5001-6000 \mathrm{TL}$ & 51 & 186,01 & & \\
\hline & 6001-7000TL & 44 & 199,89 & & \\
\hline \multirow{6}{*}{$\begin{array}{l}\text { 21. Yüzyıl } \\
\text { Becerileri }\end{array}$} & 2000 TL ve altı & 59 & 222,81 & \multirow{6}{*}{9,39} & \multirow{6}{*}{0,09} \\
\hline & 2001-3000TL & 114 & 203,11 & & \\
\hline & $3001-4000 \mathrm{TL}$ & 87 & 193,01 & & \\
\hline & 4001-5000TL & 49 & 206,57 & & \\
\hline & $5001-6000 \mathrm{TL}$ & 51 & 165,63 & & \\
\hline & 6001-7000TL & 44 & 226,18 & & \\
\hline
\end{tabular}


Yapılan Kruskall Wallis H testi analiz sonucuna göre; öğrencilerin aile gelirleri ile STEM ve alt boyutları arasında bir ilişki olmadığı görülmektedir.

\section{Tartışma}

Bilgi üretme ve rekabet edebilme açısından fenomen olan STEM, günümüz eğitim sisteminin vazgeçilmez bir unsuru haline gelmiştir. Yapılan analizler doğrultusunda; cinsiyet ile STEM' in alt boyutu olan teknoloji arasında anlamlı bir ilişki olduğu tespit edilmiştir. Kadın öğrencilerin teknoloji tutumlarının erkek öğrencilerden daha yüksek olduğu bulunmuştur. Elde edilen bu sonuç Yıldırım ve Türk (2018)' ün mühendislik uygulamalarında kız öğrenciler açısından sorunların tespit edilmesiyle örtüşmemektedir. Ayrıca erkek öğrencilerin 21. Yüzyıl becerileri açısından kadın öğrencilere nazaran daha yüksek tutum gösterdikleri tespit edilmiştir. Honey vd. (2014) göre STEM, kendi içindeki disiplinlerine ait ilişkilerin kurulabilmesine katkı sağlamaktadır (akt. Gencer, 2019, s.49). Bu açıdan elde edilen sonuç STEM' in eğitimsel amacına ulaşabildiği yönündedir.

İlgili okulun 10. Sınıfında öğrenim gören öğrenciler sınavla okula yerleşmişlerdir. 9. sınıflar ise okula sınavsız kayıt hakkı kazanmışlardır. Sınavla ya da sınavsız okula kayıt olan öğrenciler arasında STEM' le ilgili anlamlı bir farklılık tespit edilememiştir. Aynı sonuç 9. Sınıf ya da bir üst sinıf olan 10. sınıf arasında STEM tutumları yönünden bir farklılık olmadığını belirtmek mümkündür. Öğrenciler 10. sınıf sonunda bölüm tercih etmektedirler. Elde edilen bu sonuç öğrenciler açısından farklılık yaratmamaktadir.

Öğrencilerin anne eğitim düzeyi ile STEM tutumları arasında bir ilişki olmadığ tespit edilse bile; baba eğitim düzeyi ile STEM ve alt boyutu teknoloji arasında anlamlı bir ilişki mevcuttur. Öğrencilerin yükseklisansdoktora mezunu bir babaya sahip olmaları STEM tutumlarına etki etmektedir. ayrıca teknoloji tutumları en yüksek olan öğrencilerin babaları yükseklisans-doktora mezunudur. Bu sonucunu eğitim düzeyinin öğrencilerin bakış açısına, becerilerine etki ettiği şeklinde yorumlamak mümkün- 
dür. Baba eğitim düzeyi lisans olan öğrencilerin teknoloji tutumları en düşük düzeyde bulunmuştur. Elde edilen bu sonucun baba meslek durumu ile bağlantılı olduğu düşünülmektedir.

İlgili okulda zorunlu ya da seçmeli ders olarak verilmemesine ragmen robotik kodlama ve akıl oyunları kulüpleri mevcuttur. Seçimlik ders ya da kulüp aktiviteleri ile öğrencilerin STEM becerilerini artırıcı etkinliklerin eğitim sisteminde yer edinmesi büyük bir gerekliliktir.

Çolakoğlu ve Gökben (2017) STEM'e yönelik laboratuvar uygulamalarında alt yapı noksanlığı olduğundan yeterli düzeyde eğitime katkı sağlanamadığını belirtmektedirler. Araştırmanın yapıldığı okulda fen bilimleri derslerinin sınıf ortamında yapıldığı bilinmektektedir. Ayrıca Gökbayrak ve Karışan (2017, s.74) fen laboratuvarında gerçekleştirilen uygulamaların öğrencilerin STEM becerilerinin gelişmesinde katkısı olduğunu ileri sürmektedirler.

Bu çalışma lise öğrencileri üzerinde uygulanmış olup araştırma kapsamına sadece 9. ve 10. sınıf öğrencileri dahil edilmiştir. Mesleki eğitim veren başka okullarda uygulanması, 11. ve 12. sinıf öğrencilerine de uygulanması, farklı demografik değişkenlerin araştırmaya dahil edilmesi ileri de konuyla ilgili çalışma yapacak araştırmacılara önerilmektedir.

Öğrencilerin aile gelir durumları ile STEM ve alt boyutları arasında anlamlı bir ilişki tespit edilememiştir.

\section{Sonuç}

Fen bilimlerinin bir parçası olan kimya, fizik, biyoloji doğayı anlamayı sağlarken doğayı kullanarak insan ihtiyaçlarını karşılayabilmek için tasarım ve buluş yapma teknoloji yani mühendislik ile gerçekleştirilebilir. Matematik ise teknolojinin uygulanabilmesinde kullanılacak bir araç niteliğindedir.

Silikon Vadisi yaratısıcı olan ABD' de STEM'e yönelik projeler hemen desteklenmektedir. Ülkemizde de benzer girişimlere destek verilmesi üreten bir toplum olma yolunda ilerlemeye katkıda bulunacaktır. Ayrıca 21. Yüzyıl becerilerine (eleştirel düşünme, yaratıcılık, iletişim, işbirliği-4C) sahip olan kız öğrenciler tıp alanında ilerlemeye yönelirken mühendislik becerilerinden kaçınmaktadırlar. Kadın işgücü açısından üretmenin 
cinsiyeti olmadığını vurgularak STEM eğitiminde kadınlara yönelik pozitif ayrımcılık desteklenmelidir.

STEM mantığı eğitime girdiğinden bu yana öğrenciler üzerinde bir takım değişikliklerin gerçekleştiği, öğrenciler üzerinde farkındalık yarattığı görülmektedir. Bilim ile iç içe olma doğanın varoluşunu sorgulayabilme ve ondan en iyi şekilde yararlanabilme imkanı sağlayan STEM bir toplumun geleceğini çizmektedir. 
EXTENDED ABSTRACT

\title{
Research of High School Students' Attitudes of STEM
}

\author{
$*$ \\ Serpil Özkurt Sivrikaya
}

Kocaeli University

With the change of social structure, the transition from industrial society to information society has been in question. The purpose of knowledge societies is to produce knowledge. Generating knowledge is equivalent to managing the world. STEM literacy is important for every citizen's personal and country welfare. The way to produce knowledge passes through education. In this respect, the US-led STEM (Science, Technology, Engineering, Mathematics) has added innovations to education.

STEM; It is based on the principle of raising students in four special disciplines (science, technology, engineering and mathematics) as an interdisciplinary and practical approach. Rather than teaching four disciplines separately, it is based on a coherent learning paradigm based on real-world applications. To provide a single product by supporting the theoretical knowledge of science and mathematics in the engineering dimension. the purpose of the educational initiative; to provide critical thinking to all students, to bring them into creative problem solvers and to gain skills that will increase labor marketability.

Daşdemir et al. (2018, p.1161) study had been done was done using stem'l related purpose sampling method in studies in Turkey, sample group consisted of secondary school students is preferred, the negotiations with the know-how-achievement tests are used for data collection, analysis methods as found that content analysis is preferred.

The research was designed to measure the attitudes of high school students towards STEM. In this study, a quantitative research method was adopted and STEM attitude scale was used.

The universe of the research is composed of the students studying at the Anatolian High School located in Körfez District of Kocaeli Province. 
The research has been applied to high school 9th and 10th grade students in 2018-2019 academic year. The sample consists of 404 students. The analyzes were performed using SPSS 21 program and the significance level was accepted as 0.05 . The variance rate explained by the scale is 60,146 . The reliability was found to be 0,841 . The STEM scale has a right and medium level relation with the math sub-dimension, the right and high level with the science sub-dimension, the sub-dimension of the technology subdimension, and the medium-level, medium-level relationship with the twenty-first century skills sub-dimension.

In this study; $40.6 \%$ of the students were male and $58.4 \%$ were female. It was observed that $51.7 \%$ of the mother education levels of the students were primary school graduates and $41.6 \%$ of them were high school graduates. When the family income status of the students was examined, it was determined that $28.2 \%$ of the income was between 2001-3000 TL. In addition, it was determined that $61.1 \%$ of the students learned 9 th grade and $38.9 \%$ of them learned in the 10 th grade.

Students in the 10th grade of the related school settled in the school. Grade 9 students had the right to enroll in the school without examination. No significant difference was found between STEM and students with or without examination. It is possible to note that there is no difference in STEM attitudes between the 9th grade or the 10th grade. Students prefer the department at the end of the 10th grade. This result does not make any difference for the students.

Even if it is determined that there is no relationship between STEM attitudes and mother education level of students; There is a significant relationship between the level of father education and STEM and sub-dimension technology. The fact that students have a master's and doctoral degree affects STEM attitudes. In addition, the students with the highest attitudes of technology have a master's and doctoral degree. It is possible to interpret this result as the effect of education on students' perspective and skills. Technology attitudes of the students who have a father's education level have the lowest level. This result is thought to be related to the father's profession.

Although there is no compulsory or elective course in the related school, there are robotic coding and mind games clubs. It is a great necessity for the students to gain a place in the education system with activities 
that increase the STEM skills of students with an optional course or club activities.

STEM, which is a phenomenon in terms of knowledge generation and competitiveness, has become an indispensable element of today's education system. According to the analysis made; There was a significant relationship between gender and sub-dimension of STEM. It was found that female students' attitudes were higher than that of male students. This result does not correspond to the detection of problems in terms of female students in the engineering applications of Yıldırım and Türk (2018). In addition, it was found that male students showed higher attitudes towards female students in 21st Century studies. Honey et al. (2014), STEM contributes to the establishment of relations within its own disciplines. The result obtained from this perspective is that STEM can achieve its educational purpose.

This study was applied to high school students and only 9th and 10th grade students were included in the study. The application of different demographic variables to the research is recommended to the researchers who will be working on other subjects.

No significant relationship was found between the family income status of the students and STEM and its sub-dimensions.

Chemistry, physics and biology, which are part of the sciences, can be realized through the use of technology in design and invention technology, in order to meet human needs, by using nature while providing understanding of nature. Mathematics is a tool for the application of technology.

In the USA, which is the Silicon Valley creator, projects for STEM are supported immediately. Supporting similar initiatives in our country will contribute to progress towards becoming a producing community. Moreover, female students who have 21st century skills (critical thinking, creativity, communication, cooperation (4C) avoid engineering skills while advancing in the field of medicine.

Since the logic of STEM has been introduced, it has been seen that there have been some changes on the students and raising awareness on the students. STEM, which intertwines with science and enables us to question the existence of nature and make the most of it, draws the future of a society. 


\section{Kaynakça / References}

Akçapınar, G. ve Coşgun, E. (2019). Öğrencilerin stem kariyer tercihlerinin veri madenciliği yaklaşımı ile tahmin edilmesi. Eğitim Teknolojisi Kuram ve Uygulama, 9(1), 73-88.

Batı, K., Çalışkan, İ. ve Yetişir, M. İ. (2017). Fen eğitiminde bilgi işlemsel düşünme ve bütünleştirilmiş alanlar yaklaşımı (STEAM). Pamukkale University Journal of Education, 41(1), 91-103.

Beatty, A. (2011). Committee on highly successful schools or programs for K-12 STEM education. Washington DC: The National Academies Press. http://thescienceexperience.org/Books/Successful_STEM_ Education.pdf.

Benek, İ. ve Akçay, B. (2018). Hayal dünyamda stem! Öğrencilerin stem alanında yaptıkları çizimlerin incelenmesi. Bilim, Teknoloji, Mühendislik, Matematik ve Sanat (J-STEAM) Eğitimi Dergisi, 2(1), 79107.

Biçer, B. G., Uzoğlu, M. ve Bozdoğan, A. E. (2018). Fen bilimleri öğretmenlerinin stem hakkındaki görüşlerinin belirlenmesine yönelik ölçek geliştirme çalışması. OPUS-Uluslararası Toplum Araştırmaları Dergisi, 9(16), 551-574. DOI: 10.26466/opus.461791

Bruton, R. (2017, 27th November). Minister for education and skills. https://www.education.ie/en/Press-Events/Press-Releases/2017Press-Releases/PR17-11-27.html

Çevik, M. (2018). Impacts of the project based (PBL) science, technology, engineering and mathematics (STEM) education on academic achievement and career interests of vocational high school students. Pegem Ĕgitim ve Öğretim Dergisi, 8(2), 281-306, http://dx.doi.org/10.14527/pegegog.2018.012

Çolakoğlu, M. H. ve Günay, G. A. (2017). Türkiye'de eğitim fakültelerinde FETEMM (STEM) çalışmaları. Informal Ortamlarda Araştırmalar Dergisi (IAD), 3, 46-69.

Daşdemir, İ., Cengiz, E. ve Aksoy, G. (2018). Türkiye'de FeTeMM (STEM) eğitimi eğilim araştırması. YYÜ Ĕ̆itim Fakültesi Dergisi, 15(1), 1161-1183. 
Derin, G., Aydın, E. ve Kırkıç, K. A. (2017). STEM (Fen-TeknolojiMühendislik-Matematik) eğitimi tutum ölçeği. El-Cezerî Fen ve Mühendislik Dergisi, 4(3), 547-559.

Eroğlu, S. ve Bektaş, O. (2016). STEM eğitimi almış fen bilimleri öğretmenlerinin stem temelli ders etkinlikleri hakkındaki görüşleri. Eğitimde Nitel Araştırmalar Dergisi, 4(3), 43-67.

Gencer, A. S., Doğan, H., Bilen, K. ve Can, B.(2019). Bütünleşik STEM eğitimi modelleri. Pamukkale Üniversitesi Ĕ̆itim Fakültesi Dergisi, 45, 38-55.

Gökbayrak, S. ve Karışan, D. (2017). Stem etkinliklerinin fen bilgisi öğretmen adaylarının bilimsel süreç becerilerine etkisi. Batı Anadolu Ĕ̆itim Bilimleri Dergisi, 8(2), 63-84.

Gülen, S. ve Yaman, S. (2018). Fen bilimleri dersinde argümantasyon süreci ve stem disiplinlerinin kullanımı; odak grup görüşmesi. $Y Y \ddot{U}$ Eğitim Fakültesi Dergisi, 15(1), 1184-1211.

Güven, Ç., Selvi, M., ve Benzer, S. (2018). 7E öğrenme modeli merkezli stem etkinliğine dayalı öğretim uygulamalarının akademik başarıya etkisi. Anemon Muş Alparslan Üniversitesi Sosyal Bilimler Dergisi, 6, 73-80.

Hom, J. E. (2014, February 11). What is STEM education?. https://www.livescience.com/43296-what-is-stem-education.html.

Kılıç, S. (2016). Cronbach'ın alfa güvenirlik katsayısı. Journal of Mood Disorders, 6(1), 47-48.

Thibaut, L., Ceuppens, S., De Loof, H., De Meester, J., Goovaerts, L., Struyf, A. ...... , Depaepe, F. (2018). Integrated stem education: a systematic review of instructional practices in secondary education. European Journal of STEM Education, 3(1), 02. https://doi.org/10.20897/ejsteme/85525.

TÜZÜYEKSAV (2016). 1. Üstün Yetenekliler Eğitiminde İyi Uygulamalar Çalıştayı, 2-3 Eylül, 2016, Ankara.

Özcan, H., ve Koca, E. (2019). STEM'e yönelik tutum ölçeğinin Türkçeye uyarlanması: Geçerlik ve güvenirlik çalışması. Hacettepe Üniversitesi Eğitim Fakültesi Dergisi, 34(2), 2-15.

Uyanık, B. G. ve Günşen, G. (2017). Okul öncesi dönemde stem yaklaşımı. Akademik Sosyal Araştırmalar Dergisi, 5(42), 337-348. 
White, D. W. (2014). What is STEM education and why is it important?. Florida Association of Teacher Educators Journal, 1(14), 1-9. http://www.fate1.org/journals/2014/white.pdf. adresinden erişildi.

Yıldırım, B. ve Türk, C. (2018). Stem uygulamalarının kız öğrencilerin stem tutum ve mühendislik algılarına etkisi. Adryaman Üniversitesi Sosyal Bilimler Enstitüsü Dergisi, 10(30), 842-884, http://dx.doi.org/10.14520/adyusbd.368452.

Yıldırım, P. (2017). Fen, teknoloji, mühendislik ve matematik (Stem) entegrasyonuna ilişkin nitel bir çalışma. Atatürk Üniversitesi Kazım Karabekir Ĕ̆itim Fakültesi Dergisi, 35, 31- 55.

Yılmaz, H., Yiğit Koyunkaya, M., Güler, F. ve Güzey, S. (2017). Fen, teknoloji, mühendislik, matematik (STEM) eğitimi tutum ölçeğinin Türkçe'ye uyarlanması. Kastamonu Ĕ̆itim Dergisi, 25(5), 1787-1800.

\section{Kaynakça Bilgisi / Citation Information}

Sivrikaya, Ö. S. (2019). Lise Öğrencilerinin STEM'e Yönelik Tutumlarının İncelenmesi. OPUS-Uluslararası Toplum Araştırmaları Dergisi, 11(18), 914-934. DOI: 10.26466/opus.547459 